\title{
Moros y cristianos Hacia un mapa conceptual y geográfico en El Salvador
}

\author{
Julio Martínez* \\ Director de la Escuela de Antropología \\ Universidad Tecnológica de El Salvador \\ juliomartinezrivera@gmail.com
}

DOI: http://dx.doi.org/10.5377/koot.v0i8.5875

URI: http://hdl.handle.net/11298/390

\section{Resumen}

El artículo trata acerca de aspectos claves ligados a la danza de los historiantes o "moros y cristianos" en El Salvador, entre ellos se aborda lo relativo a las formas de inserción cultural en el imaginario de la población. Se abordan también temáticas acerca de cómo los significados y dinámica de las historias que forman el repertorio de "los historiantes". La música de los historiantes a diferencia de las historias, es más local y desarrollada por los grupos de danzantes y músicos que les acompañan. Se determina, además, las poblaciones donde se han establecido los historiantes generalmente corresponden a antiguos poblados indígenas donde los españoles ya sean como colonizadores o evangelizadores establecieron la tradición, enseñándola a los pueblos originarios. Se hace alusión también a la manera en que son percibidos los historiantes por las organizaciones indígenas y las contradicciones existentes. Finalmente se presenta un mapa geográfico de los pueblos con sus fiestas patronales y fechas de presentación de los historiantes.

Palabras claves: moros, cristianos, danza, historiantes

\begin{abstract}
The article discusses key aspects related to the dance of the Historiantes or "Moors and Christians" in El Salvador, among them, the forms of cultural integration in the imaginary of the population. Also addresses topics about how meanings and dynamics of the stories that form the repertoire of "Historians".

The music of the Historiantes unlike the stories, is more local and developed by groups of dancers and musicians who accompany them. It determines also the populations where they have established the Historians generally correspond to originaries villages where the Spanish colonizers or whether as evangelizers established tradition, teaching it to native peoples. Reference are also made to the way they the Historiantes are perceived by indigenous organizations and the

\footnotetext{
* Julio Martínez Rivera, es Licenciado en Trabajo Social, Maestro en Administración de la educación superior, posgraduado en Antropología Social, Maestro en Investigación y docencia y Doctorando en Estudios Sociales de América Latina por la Universidad de Alicante, actualmente es Director de la Escuela de Antropología de la Universidad tecnológica.
} 
contradictions about the tradition. Finally a geographical map of the villages with their festivals dedicated to the saint of the village and dates of submission of the Historians presented.

Keywords: Moors, Christians, dance, Historiantes

\section{Metodología del estudio}

La planeación del proceso investigativo acerca del mapa conceptual y geográfico de los historiantes siguió este proceso:

- Visualización del problema de estudio y afinamiento de dicho problema para identificar fuentes, categorías y variables.

- Estudio de fuentes documentales históricas en lo posible, locales y españolas

- Identificación de sitios y municipios donde existen los historiantes

- Identificación de fechas de las fiestas patronales y patronos por medio de fuentes diversas, documentales, electrónicas y personales

- Visitas de campo que consolidan un conocimiento previo

- Entrevistas con pobladores

- Entrevistas con miembros y ex miembros de grupos de historiantes

- Registro fotográfico

- Definición y ajustes del proyecto temático en la medida de nuevos hallazgos

- Preparación del informe.

Una ventaja de la realización del estudio en campo es que los sujetos del estudio, los historiantes se presentan con mucha confianza y amplitud para ofrecer información.

El acercarse a las localidades probablemente hace que el historiante perciba un interés auténtico en torno a su quehacer.

Hay obstáculos, desde luego:

- Algunos sitios forman parte de los lugares de peligrosidad por la violencia existente en la actualidad

- Si no se ha concertado una cita previa, es menos fácil lograr la entrevista. La cita previa requiere de contactos y teléfonos no siempre disponibles. 
- En algunos sitios se percibe desconfianza hacia el extraño.

- Por efectos de las cosmovisiones distintas entre los investigadores y los entrevistados, se requiere un esfuerzo empático.

Sistematizar la información requiere de visualizar los objetivos y a partir de ellos construir las variables que se convierten en los ejes centrales del proyecto temático.

A partir de ello, el proyecto temático puede ampliarse o reducirse, de acuerdo a la información disponible, en este caso se amplió de forma significativa.

\section{¿Qué son los Moros y cristianos?}

Teatro o fiesta de moros y cristianos es la puesta en escena de los acontecimientos relacionados con la expulsión de los moros de España luego que ellos hubieron ocupado una buena parte del territorio habitado por los visigodos.

Este proceso que se ha dado en llamar ocupación musulmana en la península ibérica fue un proceso que duró desde el 711 hasta el 726 de nuestra era para que los moros se establecieran.

"La fiesta de Moros y Cristianos se celebra en casi toda España, pero sobre todo en el Levante, en la zona de Alicante y la Comunidad Valenciana. Con esta fiesta, se conmemora la Reconquista, o sea la época histórica de la lucha entre los cristianos y los árabes (moros), que duró casi 800 años, desde 711 hasta 1492”.( Santelman, 2002, pg. 3)

Hubo momentos históricos en que esta fiesta fue "soldadesca", queriendo significar con ello que existió un culto hacia los grupos de militares vencedores, en el que seguramente se premió la heroicidad, el arrojo, la valentía, como una forma de agradecimiento popular hacia los defensores y recuperadores del territorio español.

Durante los siglos XV al XVIII en toda España se celebraron espectáculos de moros y cristianos: Toledo, 1586; Denia, 1599; Valencia, 1755; Alicante, 1700 y 1724. Pero no eran fiestas populares ya que estaban organizadas por la Corte y por las clases altas, limitándose al pueblo a ser espectadores, así como tampoco se les daba una continuidad anual (Sempere Martínez, 2012, pg. 10)

Una de las primeras impresiones que se tienen en América por parte de los estudiosos de las fiestas o teatro de moros y cristianos es que son los conquistadores españoles los que impulsan el proceso de inserción del tema en la población indígena. 
El proceso de conquista se establece desde el aparecimiento de los primeros soldados a inicios del siglo XVI después de los avistamientos realizados por Colón. En algunos lugares de América la conquista tuvo lugar incluso a finales del siglo XVIII por parte de los españoles.

En nuestra región la conquista se entrecruza con los procesos de colonización, de tal forma que las ocupaciones de españoles para la producción y explotación del territorio y población, así como la evangelización se realizan en paralelo a los procesos de dominación violenta.

Sin embargo, no tenemos una data exacta de cuando se comenzaron las fiestas de moros y cristianos en la Nueva España y Goathemala. Es claro que no fue durante la conquista sino durante la colonia, y es seguro que las primeras fiestas se realizaron en España y no en América, donde las fiestas debieron comenzar a realizarse a partir del siglo XVII como la fecha probable más antigua, sino después.

La fiesta de moros y cristianos asume nombres diferentes en diferentes lugares del mundo, así en Filipinas se conoce con el nombre de "Moro moro", aunque no siempre comprendido por la población española ocupante del territorio:

"Así la principal razón por la que los funcionarios españoles destinados a Filipinas no podían entender un teatro de base hispánica era la estética, la lengua y sobre todo constituir un entretenimiento netamente filipinizado" (Donoso, 2012, pg. 14)

En Nicaragua también existe algo parecido, llamado "El Güegüense", con clara influencia hispánica, trajes, y teatro similar:

...piezas relacionadas con la conquista de los españoles y con la resistencia de los indígenas. Piezas que parecen haber sido construidas bajo el patrón de lo que en España se llaman representaciones de moros y cristianos, en las que el conflicto entre el moro y el cristiano se ve desplazado hacia la órbita de la lucha entre el indio y el español... (Pedrosa, 2007, pg. 1)

En otros países, como Guatemala se conoce con el nombre de "la danza de la historia" en la región de Jutiapa, y como "La historia" o "Moros y cristianos" en otras zonas.

En El Salvador, se asume el nombre genérico de "Los historiantes" en casi todos los pueblos donde se celebra la fiesta. A mucha gente no le suena a nada el nombre de "Moros y cristianos", e incluso algunos llegan a pensar que son dos fiestas distintas, "Los historiantes" es un nombre más popularizado de esta fiesta. 


\section{Percepción de la llegada de la llegada de Los Historiantes a nuestra cultura}

La manera como se establecen Los historiantes en la cultura del pueblo no es suficientemente clara, incluso entre personas con formación académica hay ciertas dudas sobre el origen de la danza y parlamentos o textos. En adelante se usará parlamentos para referirse a los guiones del teatro de moros y cristianos o historiantes.

Aun cuando se utiliza de manera ambigua los conceptos de danza y baile, haremos distinciones: La danza es un arte que a través de movimientos tiene un significado simbólico. El baile es entretenimiento, y aun cuando igualmente utiliza movimientos, estos son al gusto y criterio del bailador.

Uno los antiguos miembros del grupo de Historiantes de Cuisnahuat, acerca de la llegada de la tradición de los historiantes solo pudo decir que:

"La danza llegó de Teotepeque, después a Ishuatán, y hasta después a Cuisnahuat, más antes no sé. No, no sé quién hizo la historia, lo que le puedo decir es que ya no viven" (Moisés, 2016)

No es extraño que suceda esto, pues no ha existido una sistematización de la danza o teatro, los abordajes acerca de los historiantes, los más antiguos quizá sean los de María de Baratta, y tangencialmente también los aborda Dagoberto Marroquín en el caso particular de la Monografía de Panchimalco.

Por cierto, Marroquín (1974) considera los elementos culturales de Los historiantes como de un valor secundario, fundamentalmente porque en su idea, el hecho de que las historias tuvieran anacronismo, y que además se incluyeran elementos propios de la cultura de los pueblos originarios, los hacía de menos valor en contrario de considerarlos enriquecidos y estudiar las razones que promovieron dicho enriquecimiento:

"Los anacronismos de estos relatos son notables. Nuestro famoso y popular bandido Partideño aparece colocado como Rey Moro, así como los emperadores aztecas y sus ayudantes... también interludios de recitación en los cuales los danzantes vociferan a través de las máscaras los mal aprendidos versos de los libretos en forma tal que es imposible captar el sentido de la recitación..." (Marroquín, 1980)

Reviste importancia que se pueda desarrollar un estudio acerca de cómo los parlamentos, los personajes, el sentido de las historias han evolucionado a lo largo del tiempo, una tarea muy difícil considerando la ubicación de las fuentes. Hay casos en los que el teatro no cuenta con parlamentos, o al menos existe la idea que no hay tales parlamentos, como bien lo mencionan en Cuisnahuat: 
"El equipo (grupo) que está ahora solo tiene movimientos, ni hablan ni conocen la historia" (Moisés, 2016)

La danza parece tener un mayor arraigo cultural que los parlamentos, textos o historia. Quizá por ello, es que hay algunos casos en los que el origen extranjero de la historia es difuso, y en otros ni siquiera se sabe:

"Son de lejos, de Francia, de España, ahí lo dice, hasta de Finlandia, solo que hay unos que entienden la historia y otros que no entienden nada" (Ramón, 2016)

En este nivel de comprensión de las historias, la danza y el teatro parece existir una versión ingenua de la inserción de la historia. No pasa a todos por igual; desde la perspectiva de algunos se atribuye una intencionalidad ideológica en la enseñanza de los historiantes:

"Las historias nacen de los cristianos en su lucha contra los moros, ellos tenían sus propios dioses como Mahoma, así que la historia la trajeron los frailes y los españoles" (Vasquez, 2016)

Como se nota, existe la certeza que detrás de la historia hay un afán de influir en el pensamiento de los pueblos originarios y, además, de mostrar que el Dios cristiano es más poderoso que los "otros dioses" de los musulmanes.

La religión de acuerdo a esta explicación se auxilió de los moros y cristianos para introducirse en la ideología y la cultura de los indígenas. Sin embargo, Cortez y Larraz en 1776 expresa:

"Asimismo ha notado, que unos bailes que usan los indios en sus fiestas y llaman historias de moros, se atreven con notable desacato a danzarlos dentro de las propias iglesias, a que concurra mucho número de gente de ambos sexos y de todas las edades y que lo más que ha conseguido es, que salen a hacer dichas danzas en el cementerio..." (Cortez y Larraz, 2000)

Cortez y Larraz español como es, parece desconocer la danza o "baile" como lo llama, de los historiantes, o en su descripción, "historias de moros", a los que considera en cierta forma irreverentes. La región de nacimiento del cura, Zaragoza, es alejada de la zona con mayor incidencia de los historiantes en España como indicado por Santelman (2002), lo que podría explicar el hecho de que él asume una postura de no saber sobre la historia.

Los relatos de Los historiantes, generalmente abordan el tema de la supremacía de los cristianos, basados en la expulsión de los moros del territorio español. ¿Por qué, pues, no mostrar la victoria de los cristianos y así mostrar el poder del dios para el 
que se estaba evangelizando?, eso daría sentido a la postura de instrumentalizar a los historiantes para ideologizar al indígena:

“Así para que dejaran de creer (en sus propias historias), la religión católica pensó y enseñó los historiantes” (Vasquez, 2016)

No es extraño, los procesos de dominación de los pueblos, implican también lograr el sometimiento ideológico, así vemos hoy día eventos en los que, a través de la música, el consumismo, la moda, se ejercen las dominaciones, el ejercicio del poder no tiene por qué ser violento físicamente, la violencia puede llegar de maneras sutiles.

También existen hoy día conflictos en los que los dominantes se encargan de borrar los elementos culturales identitarios de los vencidos, como en el caso de Sarajevo y la destrucción de la biblioteca por parte de los serbios en 1992.

\section{Acerca de las historias}

Las historias que se abordan integran temáticas distintas, aunque todas vinculadas a batallas y santos, religión y milicia se juntan en estas historias, tal y como también se juntaron estas dos categorías durante el proceso de conquista y colonización.

Algunos de los nombres que recién las historias son El Rey y San Bartolomé, La Batalla, el rey Carlos Magno, El rey Carlos V, Los doce pares de Francia, Los Corintios, Taborlan, Santa Marta, El renegado del cielo, Fernando II, Ganzul y el cerco de Zamora, el gran Taborlan de Persia, El Duque de Medina, David y Goliat, Los diablos con San Bartolomé, el famoso Rey de Toledo y otros más. Muchas personas no conocen las historias, Los historiantes son comprendidos mayormente como una danza y no como un teatro como originalmente parece haber sido compuesto.

Los grupos tampoco son muy sistematizadores y todo apunta a que prontamente la danza teatro será solamente una danza y posiblemente ni eso, quizá la tendencia que se evidencia hoy, a seguir en declinación surta el efecto del desaparecimiento.

"Aquí introdujeron la historia y la danza lo hacen para que sea más gracioso, la historia en el original dura dos horas, ahora el equipo (grupo) solo lo hacen con duración de media hora, solo los pasecitos así, ni hablan" (Moisés, 2016)

En algunos pueblos como Izalco, por ejemplo, hay una tradición importante de Los historiantes, probablemente los trajes más vistosos y el grupo más grande se encuentre en este municipio. 
Sin embargo, la tradición de la religiosidad católica es debilitada por la aparición de otros grupos religiosos evangélicos protestantes, a los que algunos de los miembros se adhieren.

Esto es particularmente importante porque la fiesta de Los historiantes en todo el país se vincula con las cofradías y las fiestas patronales. No hay Historiantes sino hay fiesta patronal. La fiesta patronal sin Historiantes (donde existen grupos) no es completa.

"los historiantes es un baile cristiano, siempre va junto con la fiesta del patrono" (Martínez, 2016)

Así se puede determinar la importancia de la evangelización en el aparecimiento de la fiesta de la historia, tal como en España, pero de forma inconsciente, se presentan a la par de la fiesta del patrono, como un elemento de agradecimiento hacia la religiosidad que logró dar fuerzas al ejército católico para la expulsión de los moros.

Habrá otros casos en los que no hay conocimiento del origen de la fiesta misma, "La mayoría de la gente piensa que es de los pueblos originarios, se desconoce lo que es la tradición, y solo quieren ver el baile, los movimientos les gustan más que todo". (Vasquez, 2016)

\section{La música en Los historiantes}

La música de los historiantes es muy autóctona y muy poco compleja, generalmente se hace acompañar de pito y tambor, como las otras danzas tradicionales como el tigre y el venado, el torito pinto, los compadres, los diablitos, la danza de la soguilla, la danza de la vaca, la danza del zope, la danza de los cucuruchos, La garza y otros más.

Se usa pito (carrizo de caña) y tambor (teponahuaste en los más antiguos) como elementos sincréticos, que emulan a los pitos y tambores usados originalmente en la zona mediterránea de España, siendo pues que un buen grupo de españoles colonizadores provinieron de esa región, que es además donde con mayor fuerza se impulsan las fiestas de moros y cristianos en Europa.

Sin embargo, este pito y tambor son locales, ambos son más indígenas mientras que:

"la historia es del ladino, pero la música es del indio, la historia se hizo para que dejaran de creer, es la religión que hace la historia y los pueblos, los naturales los que hacen la música" (Vasquez, 2016) 


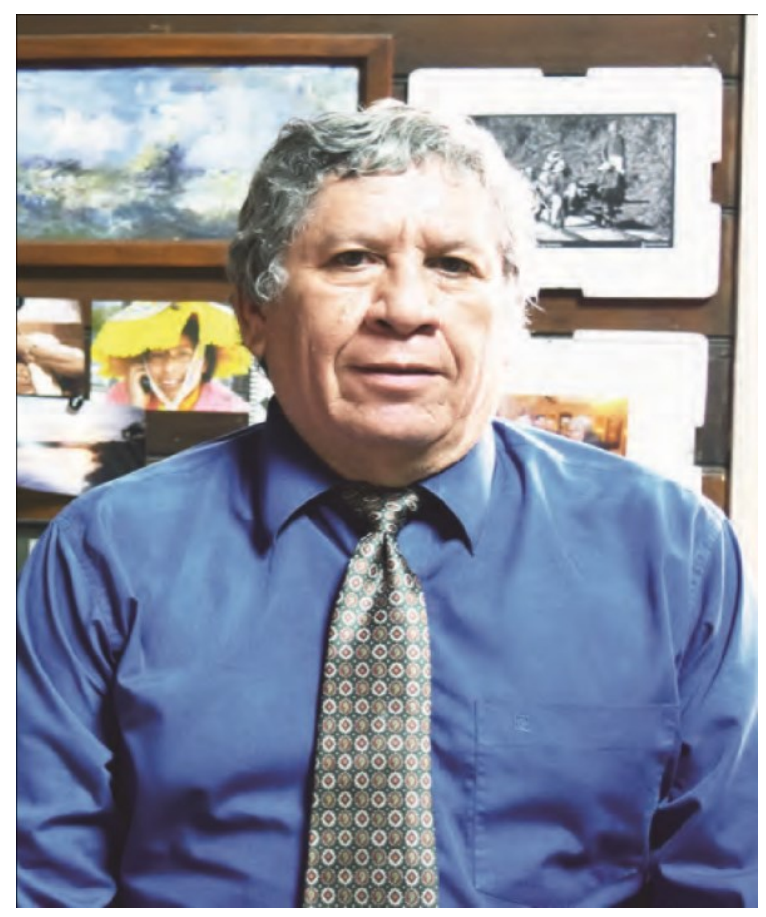

Julio Martínez

Se establece una diferencia en el origen los componentes de la historia, ladinos e indígenas. Esto también lo confirman en Cuisnahuat:

"No hay historias propias" (Moisés, 2016)

\section{Los historiantes y la población}

La relación de Los historiantes como tradición y no como miembros de un grupo es dicotómica, es un "sí pero no". Hoy día los jóvenes que serían los llamados para iniciarse en los grupos y así dar continuidad a los grupos, está más bien alejada del mismo.

En Cuisnahuat, el comentario de los más jóvenes nos indica que probablemente no sean muchos años más de tradición:

"Yo no soy indio para hacer eso" (Moisés, 2016)

Los procesos neocolonizadores ya no requieren de la utilización de las armas necesariamente, hoy día se han transformado en procesos globalizadores, logran 
incidir tanto en lo ideológico cultural que el amor por las tradiciones es visto más bien como un antivalor, jóvenes originarios no desean ser vistos como "indios" en la medida que el concepto fue acuñado durante los años de la colonización con carácter de sometimiento y con mayor fuerza durante los gobiernos liberales del siglo XIX como un adjetivo despectivo.

El "indio" pasó a ser una categoría de persona que era borracho, haragán y malhablado como un estereotipo. "Yo no soy indio" también quiere decir, "yo no quiero ser indio, quiero ser moderno", ahí el alejamiento y el renegar de la propia condición.

Los habitantes de los pueblos donde en la actualidad existen Historiantes son aficionados al teatro, a la fiesta, sin embargo:

"la gente quiere que siga la danza, pero no colaboran" (Moisés, 2016)

No parece existir muchísimo interés en conocer más acerca de la danza, y siendo que los sentimientos de los pobladores urbanizados de los pequeños pueblos es que se sienten mayormente ladinizados, no han interiorizado la danza como un elemento que le permite autodefinirse y generarse una identidad, esa identidad es para el "natural", para el indígena.

En general, pocos tienen una clara consciencia acerca del simbolismo de la danza:

"La mayoría de la gente piensa que es de los pueblos originarios, se desconoce lo que es la tradición. Fuera de acá del pueblo, la gente solo quiere ver el baile, no están interesados en las historias" (Vasquez, 2016)

\section{Auto percepción}

Los historiantes forman parte de una tradición que tiene un doble sentido:

- Por un lado, no es la historia de los pueblos originarios, aunque muchos la perciben así. Existe en algunos la claridad de que las danzas son extranjeras, impuestas culturalmente desde la religión.

- Por otro lado, hay un sentimiento de tener la necesidad de seguir la tradición, la danza ha pasado a formar parte de su identidad. Como un elemento cultural insertado en el imaginario del danzante.

"A los que danzamos la historia nos toca entender como es, es nuestra tradición, y por ello, aunque uno entiende que no es nuestra originalmente, quiere aferrarse a la tradición. Sin embargo, en las organizaciones de pueblos indígenas, nos dicen que es occidental, que no es nuestro. En la organización indígena no hablamos de los historiantes, este es un asunto que no cuenta para los otros pueblos indígenas" (Vasquez, 2016)

En El Salvador existen varias organizaciones de pueblos indígenas, a saber: 


\begin{tabular}{|c|c|}
\hline $\begin{array}{l}\text { Organizaciones Indígenas integrantes de } \\
\text { CCNIS }\end{array}$ & $\begin{array}{l}\text { Organizaciones Indígenas no } \\
\text { integrantes de CCNIS }\end{array}$ \\
\hline $\begin{array}{l}\text { Movimiento Autóctono Indígena } \\
\text { Salvadoreño - MAIS }\end{array}$ & $\begin{array}{l}\text { Asociación Coordinadora de Comunidades } \\
\text { Indígenas de El Salvador - ACCIES }\end{array}$ \\
\hline $\begin{array}{l}\text { Asociación Nacional Indígena Tierra } \\
\text { Sagrada - ANITISA }\end{array}$ & $\begin{array}{l}\text { Asociación Cultural Indígena de Cuscatlán } \\
\text { - ACIC }\end{array}$ \\
\hline $\begin{array}{l}\text { Asociación Nacional Indígena } \\
\text { Salvadoreña - ASNAIS }\end{array}$ & $\begin{array}{l}\text { Asociación Cooperativa de Producción } \\
\text { Agropecuaria y Servicios Múltiples El } \\
\text { Papalote R .L. - ACPASEMU }\end{array}$ \\
\hline $\begin{array}{l}\text { Asociación para el Rescate de la Cultura } \\
\text { Autóctona Salvadoreña-ARCAS }\end{array}$ & Winaka (Comunidad Kakawira) \\
\hline $\begin{array}{l}\text { Asociación Democrática de los } \\
\text { Trabajadores Agropecuarios Indígenas } \\
\text { Salvadoreños - ADTAIS }\end{array}$ & $\begin{array}{l}\text { Asociación Nacional Indígena Salvadoreña de } \\
\text { la Tercera Edad - ANISTED }\end{array}$ \\
\hline $\begin{array}{l}\text { Consejo Nacional Indio Salvadoreño - } \\
\text { CONAIS }\end{array}$ & $\begin{array}{l}\text { Asociación de Pueblos Indígenas Mayas de } \\
\text { Cuscatlán - APIMAYCU }\end{array}$ \\
\hline $\begin{array}{l}\text { Artistas para la Revivificación de la } \\
\text { Cultura Original - ARCO }\end{array}$ & $\begin{array}{l}\text { Asociación Salvadoreña para el Desarrollo } \\
\text { Integral Indígena - ASDEI }\end{array}$ \\
\hline $\begin{array}{l}\text { Asociación Comunal Lenca de } \\
\text { Guatajiagua - ACOLGUA }\end{array}$ & $\begin{array}{l}\text { Asociación de Tallado de Madera y } \\
\text { Carpintería de Izalco Tito Armando } \\
\text { Campos - ATEMITAC }\end{array}$ \\
\hline $\begin{array}{l}\text { Asociación Nacional Indígena Náhuat } \\
\text { Pipil de Izalco - ANIMPI }\end{array}$ & $\begin{array}{l}\text { Consejo de Mujeres Principales Náhuat del El } \\
\text { Salvador-COMUPRIN }\end{array}$ \\
\hline Alcaldía del Común de Izalco & $\begin{array}{l}\text { Consejo de Principales Aj'quijab' } \\
\text { (Sacerdotes Mayas) de El Salvador }\end{array}$ \\
\hline $\begin{array}{l}\text { Mesa Nacional Indígena de Tecoluca - } \\
\text { MITEC }\end{array}$ & $\begin{array}{l}\text { Consejo de Pueblos Indígenas de } \\
\text { Occidente - CPIO }\end{array}$ \\
\hline $\begin{array}{l}\text { Asociación de Artesanos de El Salvador } \\
\text { - ITZAMA }\end{array}$ & Fundación Ama - FAMA \\
\hline $\begin{array}{l}\text { Asociación Cultural Ecológica Indígena } \\
\text { Salvadoreña - ACEIS }\end{array}$ & $\begin{array}{l}\text { Instituto Para el } \quad \text { Rescate Ancestral } \\
\text { Indígena Salvadoreño - RAIS }\end{array}$ \\
\hline $\begin{array}{l}\text { Asociación para el Desarrollo Comunal } \\
\text { Indígena de Santo Domingo de Guzmán - } \\
\text { ADESCOIN. }\end{array}$ & Movimiento Sihuat \\
\hline $\begin{array}{l}\text { Asociación Agropecuaria para el Medio } \\
\text { Ambiente y la Cultura de Santiago } \\
\text { Texacuangos - AMACTEX }\end{array}$ & \\
\hline
\end{tabular}

Fuente: Mario Mata y Julio Martínez, "Análisis del movimiento social: Organizaciones campesinas, indígenas y trabajadores/as del campo", El Salvador, 2009 
Sin embargo, a pesar de que son los pueblos indígenas los que participan en la organización de los historiantes, las organizaciones de pueblos indígenas no expresan afinidad por los historiantes, esto obedece a una cuestión ideológica, política y fundamentada en las antiguas relaciones conquistador - conquistado, y las subsiguientes formas de relación en la colonia entre el indígena y el español.

\section{Distribución de los historiantes en el país}

Claramente los historiantes se desarrollan en poblados en donde existe una celebración o fiesta patronal, siguiendo el esquema español.

Los poblados se concentran de forma no exclusiva en los departamentos de Sonsonate, La libertad, Ahuachapán, San Salvador y La paz, siguiendo una lógica de agrupación en torno a estos municipios del occidente y del centro del país.

Como hemos expresado previamente en estos pueblos existe la organización católica popular de la cofradía, que se encargan de las fiestas patronales. Estos cofrades acuden los historiantes para celebrar al santo o santa.

\section{MUNICIPIOS, FECHAS Y PATRONOS}

\begin{tabular}{|c|c|c|}
\hline Departamento y municipios & fecha & Patrono \\
\hline \multicolumn{3}{|c|}{ Muni cipios del departamento de Ah uachapán } \\
\hline Concepción de Ataco & 11-15 de diciembre & Inmaculada Concepción de María \\
\hline San Pedro Puxtla & 27 al 29 de agosto & San Pedro Apostol \\
\hline Tacuba & 19 al 22 de julio & Santa María Magdalena \\
\hline \multicolumn{3}{|c|}{ Mu nicipios del departamento de S anta Ana } \\
\hline \multicolumn{3}{|c|}{ NO HAY } \\
\hline \multicolumn{3}{|c|}{ Mun icipios del departamento de So nsonate } \\
\hline Cuisnahuat & 27 al 30 nov & San Lucas Evangelista \\
\hline Izalco & 8 al 16 de agosto & Virgen del Tránsito y Asunción \\
\hline Nahuizalco & 20 al 25 de junio & San Juan Bautista \\
\hline Salcoatitán & 2o domingo de noviembre & San Miguel Arcangel \\
\hline Santa Catarina Masahuat & 23 al 25 de noviembre & Santa Catalina de Alejandría \\
\hline Santa Isabel Ishuatán & 29 al 30 de noviembre & Santa Isabel \\
\hline Santo Domingo Guzmán & 1 al 4 de agosto & Santo Domingo de Guzman \\
\hline \multicolumn{3}{|c|}{ Muni cipios del departamento de Cha latenango } \\
\hline Tejutla & 18 al 20 de diciembre & Santo Tomás Apostol \\
\hline \multicolumn{3}{|c|}{ Mu nicipios del departamento de C uscatlán } \\
\hline \multicolumn{3}{|c|}{ NO HAY } \\
\hline \multicolumn{3}{|c|}{ Muni cipios del departamento de San Salvador } \\
\hline Ciudad Delgado & 25 al 26 de julio & San Sebastián \\
\hline Panchimalco & $\begin{array}{l}12 \text { al } 14 \text { de septiembre, } 7 \text { de octubre y del } 3 \text { al } 5 \\
\text { de mayo }\end{array}$ & Santa Cruz de Roma y Virgen del Rosario \\
\hline San Martín & 10 al 11 de noviembre & San Martín Obispo \\
\hline San Salvador & 12 de enero / 16 de julio & San Antonio Abad / Cantón El Carmen \\
\hline Santiago Texacuangos & 24 al 25 de julio & Santiago Apostol \\
\hline Santo Tomás & 20 al 21 de diciembre & Santo Tomás Apostol \\
\hline \multicolumn{3}{|c|}{ Mun icipios del departamento de La Libertad } \\
\hline Huizúcar & 28 al 29 de septiembre & San Miguel Arcangel \\
\hline Jayaque & 14 al 20 de enero & San sebastián Mártir \\
\hline Jicalapa & 2 al 4 de febrero & Santa Ursula \\
\hline Talnique & 24 al 25 de agosto & San Luís, Rey de Francia \\
\hline Talnique & 24 al 25 de agosto & San Luís, Rey de Francia \\
\hline
\end{tabular}

(C)Universidad Tecnológica de El Salvador 
URI: http:/hdl.handle.net/11298/390

\begin{tabular}{|c|c|c|}
\hline \multicolumn{3}{|c|}{ Muni cipios del departamento de Sa n Vicente } \\
\hline Apastepeque & 20 de enero & San Sebastián \\
\hline San Vicente & 15 al 31 de diciembre & San Vicente Abad \\
\hline \multicolumn{3}{|c|}{ Mu nicipios del departamento de $\mathrm{C}$ abañas } \\
\hline Ilobasco & $\begin{array}{l}26 \text { al } 29 \text { de septiembre, cantón } \\
\text { Las Huertas }\end{array}$ & San Miguel Arcángel \\
\hline \multicolumn{3}{|c|}{ M unicipios del departamento de La Paz } \\
\hline San Francisco Chinameca & 15 al 17 de septiembre & San Francisco de Asís \\
\hline San Juan Tepezontes & 24 al 29 de diciembre & San Juan Evangelista \\
\hline San Miguel Tepezontes & 25 al 29 de septiembre & San Miguel Arcangel \\
\hline San Pedro Nonualco & 1 al 6 de febrero / 25 al 29 de junio & $\begin{array}{l}\text { Dulce Nombre de Jesús /San Pedro } \\
\text { Apostol }\end{array}$ \\
\hline Santiago Nonualco & $\begin{array}{l}16 \text { de julio, Santiago Apostol/ } \\
22 \text { al } 25 \text { de julio }\end{array}$ & Santiago Apostol \\
\hline \multicolumn{3}{|c|}{ Mu nicipios del departamento de U sulután } \\
\hline Alegría & 26 al 29 de septiembre & San Miguel Arcángel \\
\hline \multicolumn{3}{|c|}{ Mun icipios del departamento de Sa n Miguel } \\
\hline \multicolumn{3}{|c|}{ NO HAY } \\
\hline \multicolumn{3}{|c|}{ Mu nicipios del departamento de Morazán } \\
\hline \multicolumn{3}{|c|}{ NO HAY } \\
\hline \multicolumn{3}{|c|}{ Mu nicipios del departamento de L a Unión } \\
\hline Conchagua & 24 y 25 de julio & Santiago Apostol \\
\hline
\end{tabular}

Los historiantes se distribuyen en el país desde la frontera con Guatemala, hasta el Golfo de Fonseca, no con igual intensidad en su distribución geográfica. Esta distribución incluye 32 grupos de historiantes en 31 municipios del país en el occidente, el centro, norte, paracentral y el oriente de El Salvador.

Todos los pueblos y municipios donde se celebran los historiantes reflejan una historia de población indígena, pero no en todos los pueblos indígenas existen historiantes, de hecho, viéndolo desde una forma positivista, los historiantes solo abarcan el $11.8 \%$ de los municipios.

No existen grupos de ladinos que establezcan o desarrollen grupos de danza de los historiantes, se considera una tradición que los pueblos indígenas desarrollan con exclusividad, y probablemente eso se deba a cualquiera de las dos hipótesis que determinan la existencia de los historiantes:

- La primera hipótesis indica que los historiantes se formaron auspiciados por los españoles durante la colonia para que ellos pudiesen ver el teatro sin participar activamente, para ello enseñaron los parlamentos a grupos de indígenas con habilidades histriónicas. Luego durante las fiestas los españoles se sentaban a entretenerse con estos grupos que hacían teatro y danza para ellos, lo que siguió fue que los indígenas asumieron la tradición y la mantuvieron hasta nuestros días. 
- La segunda hipótesis es que los curas enseñaron las historias a los indígenas para que formaran los grupos de danzantes y digirieran que el cristianismo es todopoderoso, tanto como para vencer a los musulmanes.

Como sabemos, en ciertos casos los grupos de historiantes han adaptado esas historias con personajes locales y en otros han modificado la historia de tal forma que los moros de la historia han sido asumidos por los indígenas y que inclusos en una revancha histriónica y no histórica, son los españoles los vencidos y no los vencedores.

En términos gráficos, se ha elaborado el mapa de los historiantes en el país tal como sigue:

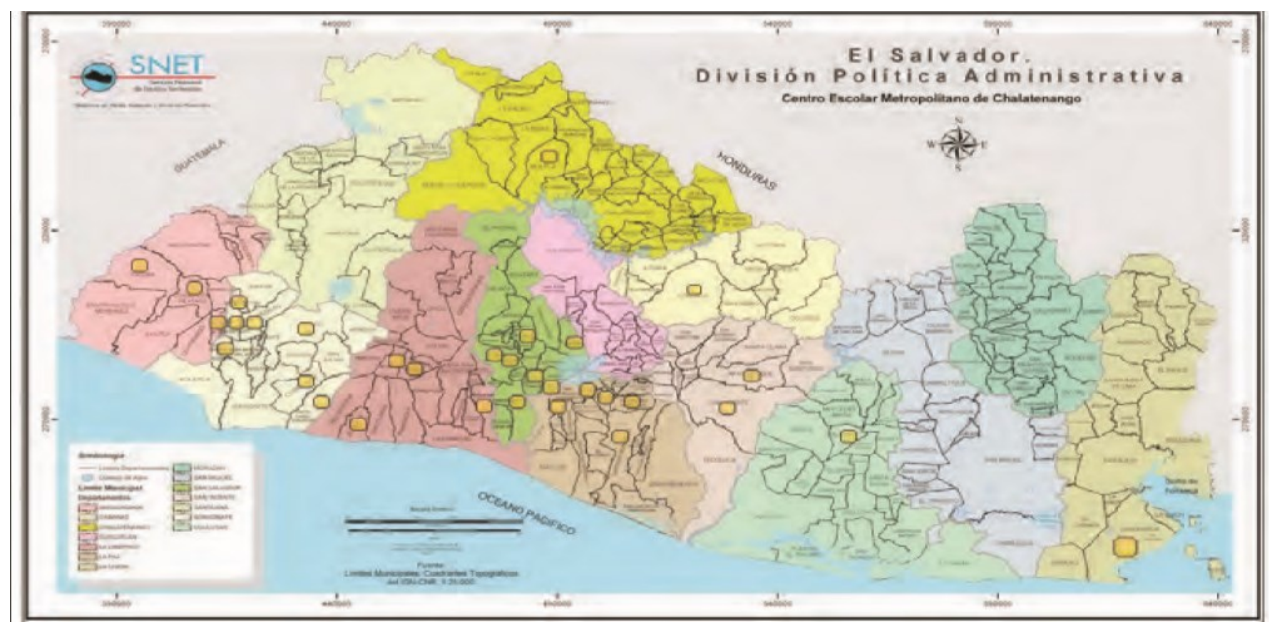

Todos los pueblos anotados han tenido o tienen una prevalencia de población de origen indígena o indígena en la actualidad, lo que reconfirma la existencia de historiantes en sociedades locales indígenas, exceptuando San Salvador y San Martín, donde la existencia actual recae en el trabajo de personajes particulares interesados en la cultura.

Una primera impresión del mapa es que existe una concentración en:

- Los municipios de la sierra Apaneca - Ilamatepec

- Los municipios cercanos a la que cordillera del Bálsamo.

- Los municipios cercanos a la sierra central

Casi todos estos municipios eran pueblos originarios o si se quiere concentraciones de poblados indígenas, en los cuáles los sacerdotes españoles establecieron sus iglesias para contribuir con los encomenderos en el proceso evangelizador. 


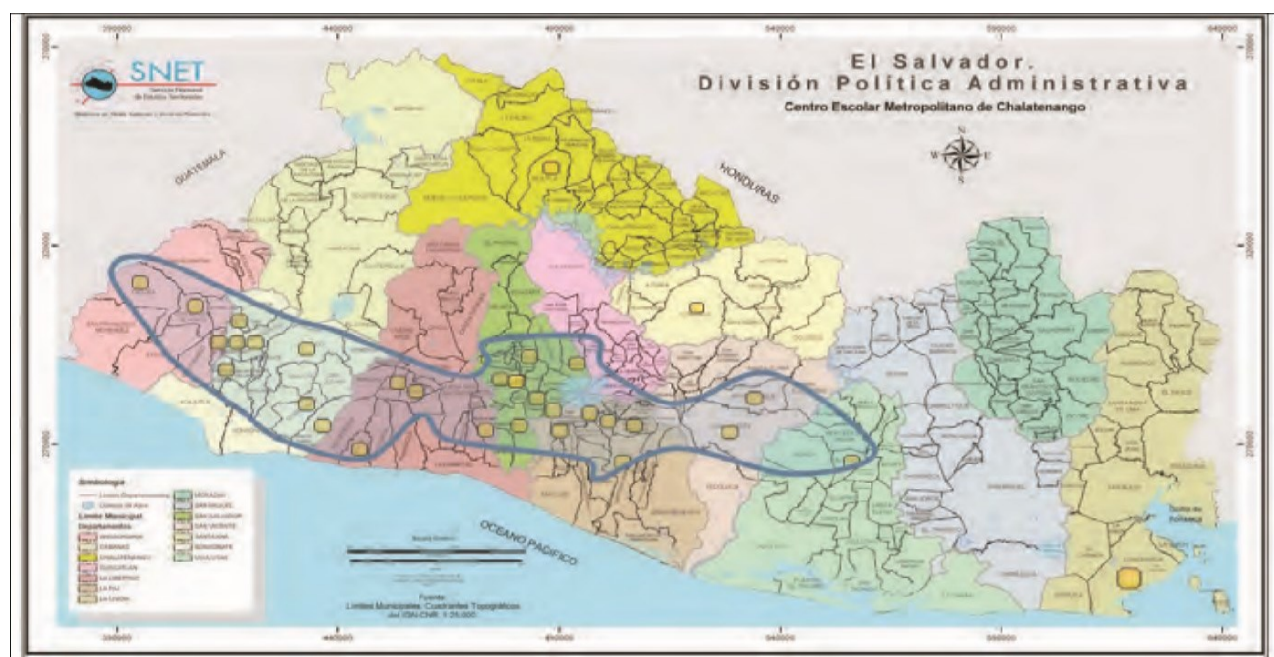

También es destacable que varios de estos pueblos juntan sus nombres originarios con los nombres de los santos a los que se advocaron, un mecanismo sincrético para la reducción de la resistencia indígena.

Las fiestas patronales de estos municipios son importantes, y requieren de un sistema de celebración que se apoya particularmente en las cofradías que cobran importancia singular en torno a la organización de los pobladores, focalmente los indígenas católicos.

Por ello es que en Santo Domingo de Guzmán se ha mencionado una crítica velada a la aparición, desarrollo y fortalecimiento de los grupos evangélicos protestantes que cooptan a cristianos católicos, incluyendo a algunos de ellos que son miembros activos de los grupos de historiantes.

Una vez que pasan a convertirse en evangélicos protestantes ya no pueden participar de las fiestas patronales que como sabemos, son católicas.

Algunos pocos pueblos y grupos de historiantes escapan de esta lógica de ubicación geográfica mas no de la influencia de los curatos, así encontramos a Tejutla en Chalatenango, Ilobasco en Cabañas, Alegría en Usulután y Conchagua en La Unión, lo que se puede explicar por el desplazamiento de sacerdotes que antes estuvieron en las zonas de concentración en el occidente y centro, o de españoles que se trasladaron a los dichos poblados para ejercer su dominio de la tierra y el indígena.

\section{Conclusiones:}

- La fiesta de Moros y cristianos se celebra en diferentes partes del mundo en donde los españoles ejercieron influencia imperial. 
- Los moros y cristianos se impulsan por grupos de colonizadores españoles como una forma de garantizar entretenimiento o por sacerdotes en los pueblos indígenas como una forma de ideologización.

- La fiesta cristiana católica en honor al santo patrón católico y las cofradías son ambos elementos promotores de los historiantes.

- No siempre es conocido ni por los miembros de los grupos de historiantes ni por los pobladores mismos el origen de la fiesta, tanto que algunos la consideran auténticamente de los pueblos originarios.

- En algunos casos, es aceptado que el parlamento obedece a una historia extranjera, pero los instrumentos musicales y la composición musical es autóctona.

- Hoy día hay una mayor tendencia a observar la danza, y obviar los parlamentos, de los que algunos miembros de los grupos son menos estudiosos.

- La información de existencia de los historiantes es del año 1776. Probablemente ya existían antes de esta fecha, pero la evidencia documental es de tal fecha.

- Las organizaciones de pueblos indígenas no se muestran a favor de la fiesta de los historiantes.

- Los pueblos que celebran esta fiesta tienen una concentración en el occidente y centro del país.

\section{Referentes bibliográficos}

Cortez y Larraz, P. Descripción geográfico moral de la diocesis de Goathemala. San Salvador, El Salvador: Dirección de Publicaciones. 2000.

Donoso, I. Historia cultural de la lengua española en Filipinas: Ayer y hoy. Madrid, España: Verbum. 2012.

Marroquín, A. Panchimalco: investigación sociológica. San Salvador, El Salvador: Dirección de publicaciones, Ministerio de educación. 1980.

Martínez, A. Nahuizalco. (J. Martínez, Entrevistador) 9 de octubre de 2016.

Martínez, J. E. Movimiento social de indígenas y campesinos. San Salvador, El Salvador: n/d. 2009.

Moisés, L. Cuisnahuat. (J. Martínez, Entrevistador) 10 de octubre de 2016.

Pedrosa, J. Mestizaje e hibridismo de El Güegüense. Especulo, 34, nd. 2007.

Ramón, T. Izalco. (J. Martinez, Entrevistador) 11 de octubre de 2016.

Santelman, C. Klett Verlag. Obtenido de www.klett-verlag.de (nd de nd de 2002).

Sempere Martínez, M. La fiesta de moros y cristianos desde sus albores.

Alicante: Graficos El Cid, S.L. 2014.

Vasquez, M. Santo domingo de Guzman. (J. Martínez, Entrevistador) 12 de octubre de 2016. 


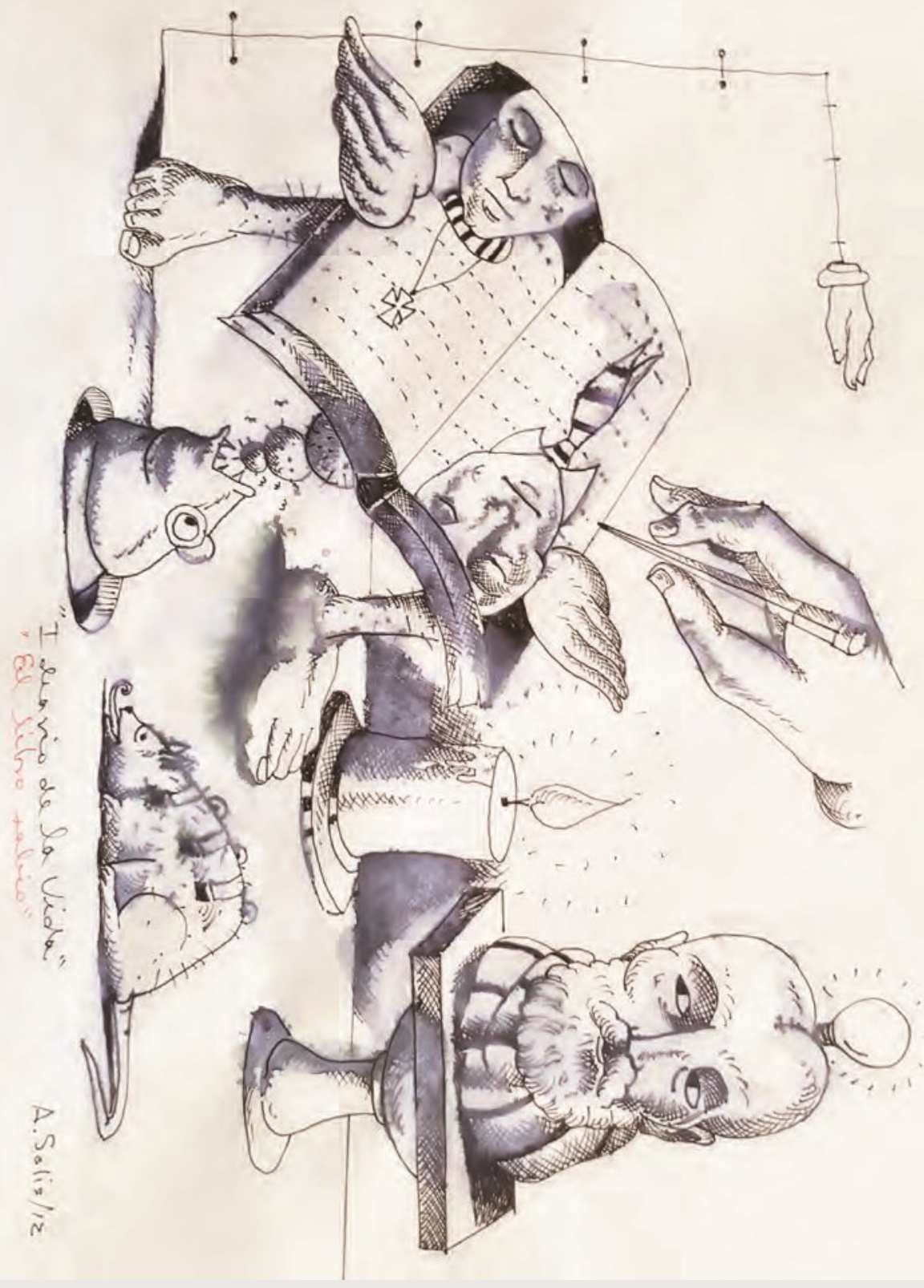

